\title{
Tesis doctoral dirigida por la Dra. Cristina Patiño Eirín y defendida en el Campus de Lugo (Universidad de Santiago de Compostela) el 5 de julio de 2018.
}

\author{
Ma del Mar Novo Díaz \\ (UNIVERSIDADE DE SANTIAGO DE COMPOSTELA) \\ marimarnovo@gmail.com
}

(recibido xuño/2020, aceptado novembro/2020)

RESUMEN: Esta reseña presenta un resumen de la tesis doctoral defendida bajo el título: Procesos y fases de reescritura en Emilia Pardo Bazán. La génesis textual de treinta cuentos. Se aglutina la investigación llevada a cabo sobre los cuentos de Emilia Pardo Bazán publicados en la prensa española y extranjera y sus fases procesuales hasta llegar al texto perfecto para la autora.

PALABRAS CLAVE: Emilia Pardo Bazán, Tesis doctoral, cuento, prensa, fases procesuales.

ABSTRACT: This review presents a summary of the content of the doctoral thesis defended under the title: Procesos y fases de reescritura en Emilia Pardo Bazán. La génesis textual de treinta cuentos. The research carried out on the short stories of Emilia Pardo Bazán published in the Spanish and foreign press and its procedural phases is brought together until the perfect text for the author is reached.

KEY WORDS: Emilia Pardo Bazán, Doctoral Thesis, short story, press, procedural phases.

El largo y arduo trabajo de investigación sobre los cuentos de Emilia Pardo Bazán publicados en prensa que durante algo más de una década he llevado a cabo culminó en el título Procesos y fases de reescritura en Emilia Pardo Bazán. La génesis textual de treinta cuentos. Nació para conocer las fases procesuales de la narrativa breve de Emilia Pardo Bazán, para mostrar cómo la autora vuelve una y otra vez sobre el relato, releyendo, corrigiendo, e incluso, en ocasiones, rehaciéndolo hasta obtener una creación adaptada al receptor, según sea un leyente casual de hojas volanderas o el fiel lector que compra su obra codificada en libro, cuyo último fin es perdurar en el tiempo como fiel testigo de una labor bien hecha. Aquí no rige el viejo principio legal de non venire contra factum propium, la creadora es quien una y otra vez revisa, corrige o rehace esos cuentos nacidos 
de su pluma y que considera merecedores de reforma, bien sea en el manuscrito o mecanoscrito, o una vez ya dados a conocer al público por medio de la prensa.

Las pesquisas han sido muy laboriosas y hasta cansinas. Al principio fueron realizadas in situ, en hemerotecas, y en años posteriores, gracias a los soportes digitales, pude agilizar la investigación. No es este un trabajo que se pueda dar por finalizado. A día de hoy siguen apareciendo nuevos textos, como se puede ver en el cuento "El Retrato" que en este mismo número de La Tribuna he rescatado de la revista madrileña ¡Alegría!

Una vez revisados los varios centenares de cuentos de la escritora coruñesa, ante un corpus tan extenso y tras muchas cavilaciones, me decanté por aquellos que mejor podían sustentar la idea rectora, la de reelaboración y revisión reiterativa de la producción por parte de Pardo Bazán. En este punto, tengo que decir que la labor pulcra y exquisita de la creadora la lleva a revisar y pulir incluso los cuentos no compilados en su Opera Omnia, caso de seis de los treinta que analizo.

Treinta relatos breves son, en efecto, el objeto final de estudio de esta tesis. Mediante su análisis genético-textual podemos conocer el modus operandi de una mujer escritora que nunca cejó en su empeño en la búsqueda de perfección, en el golpe certero del cuento, guiando y anticipando la lectura y no dejando nada al azar, ni a posibles errores de interpretación por parte de un lector crítico con su producción.

Esta treintena de cuentos se basta para demostrar, estoy persuadida de ello, el cariño y buen hacer de la escritora ante su obra. He podido determinar su secuencia genética y cada una de las modificaciones de puntuación o distribución de la masa gráfica. Cada uno de los relatos posee rasgos individualizadores que lo diferencian de los demás y justifican su trato particular y diferente en el análisis.

La Tesis doctoral consta de cinco partes:

$1^{\text {a }}$ - Génesis textual de treinta cuentos de Emilia Pardo Bazán.

$2^{\mathrm{a}}$ - Análisis genético-textual del Corpus del siglo XIX.

$3^{\text {a }}$ - Análisis genético-textual del Corpus del siglo XX.

$4^{\mathrm{a}}$ - Conclusiones y Bibliografía.

$5^{a}$ - Apéndices.

La Primera Parte comprende el estado de la cuestión y en ella presento la necesidad e importancia de explorar la ecdótica textual de los autores del siglo XIX. En el caso de Emilia Pardo Bazán, el papel de la prensa en la emisión y recepción de su producción breve es especialmente relevante. La primera salida de los cuentos se da en periódicos y revistas de la época y este es un medio que se ha tenido en cuenta en muy contadas ocasiones a la hora de editar los textos. La única labor editorial que sí tuvo en cuenta su salida en prensa con anterioridad fue la llevada a cabo, admirablemente, por la profesora Nelly Clemessy en su tesis doctoral de 1967-68 y, más recientemente, los volúmenes de Cuentos dispersos y Cuentos para las Américas llevados a cabo por José Manuel González Herrán, además de la que yo misma estoy realizando con los publicados en México. El rescate de los cuentos 
publicados en la prensa va a permitir recomponer el stemma en la elaboración del relato. Hay casos tan Ilamativos que se pueden considerar cuentos diferentes, caso de "Milagro Natural", que Pardo Bazán rehízo para su compilación en la Opera Omnia. La conexión entre prensa y literatura es indiscutible, y en este caso nos permite conocer textos que permanecen olvidados o de los que no disponemos de copia manuscrita ni mecanoscrita, pero que, como queda patente en este estudio, no se corresponden con lo recogido por su autora en las Obras Completas. Para conocer a fondo los relatos breves debemos rescatar las salidas de estos en la prensa para así acceder a otras versiones tal y como afirman José Miguel Rodríguez Rodríguez y María Angulo Egea en Periodismo literario. Naturaleza, antecedentes, paradigmas y perspectivas (2010).

En el caso concreto de Pardo Bazán no solo era periodista, se enorgullecía de serlo:

Camino de la Exposición, se abalanza al coche media docena de pilluelos que, en vez de pedir limosna, me brindan los tickets. Yo tengo mi tarjeta de periodista y no he menester entradas (las tarjetas de periodista se componen de un retrato, una firma y una autorización); pero mis niños necesitan un ticket, y no tengo valor para regatearles unos cuantos céntimos a los gavroches que tan penosamente se los ganan correteando detrás de cuantas personas se aproximan a las puertas del Campo de Marte y la Explanada de los Inválidos (Pardo Bazán [1899]: 175-176)

por lo tanto, no tiene sentido dejar de lado la salida en prensa de los cuentos optando solo por su compilación en libro cuando ella llevó a gala disponer de su tarjeta de periodista. Desconocer otras salidas del texto resta validez a la trama puesto que desconocemos los pasos ejecutados hasta llegar al que la autora consideró digno de su mano.

Como acabo de anotar, los estudios sobre las variantes textuales de los cuentos son a todas luces insuficientes y muy necesarios. Editar la publicación libresca enriquecida con las salidas de prensa permite al estudioso detectar los cambios sufridos por el relato a través de las distintas salidas a la luz y su fijación posterior en las Obras Completas.

El grueso del estudio lo constituyen la Segunda y Tercera partes. En ellas efectúo el análisis genético-textual del corpus agrupado siguiendo la compilación llevada a cabo en sus Obras Completas en Cuentos Nuevos, Cuentos de Amor, Cuentos sacro-profanos, Cuentos dramáticos, El fondo del alma, Sud-exprés, Cuentos trágicos, Cuentos de la tierra y hago un sexto apartado con aquellos cuentos que no han sido recogidos en volumen por la autora; quedando así distribuido en: Corpus del siglo XIX, que comprende el estudio de los cuentos "El cinco de copas", "La flor de la salud" / "El milagro del Doctor", "Náufragas" / "Náufragas provincianas", "Martina", "La sed de Cristo", y en: Corpus del siglo XX con el análisis de "En tranvía", "La Chucha" / "Palabra de hombre", "Inspiración" / "El modelo", "Los padres del Santo", "El tapiz", "Sin respuesta" / "La causa", "El viaje de novios de mister BigPig" / "Por España", "Primaveral-Moderna", "Paria", "Los cinco sentidos", "Por otro", "Hijo del alma", "El pajarraco", "Reconciliados" / "Reconciliación", "Milagro natural", "Antiguamente", "La salvación de don Carmelo", "En silencio", "Comadre y Compadre", Puntería", "Al anochecer" / "Los Israelitas", "Remedio infalible" / ["Un buen tirito"], "El triunfo de Baltasar", "Ejemplo" / "El enemigo". 
Los cambios operados en estos treinta cuentos dejan a la vista un talento literario y una gran sensibilidad a la hora de pulir el texto, recubriéndolo de matices y ajustando el término a la historia y al personaje. Nada queda al arbitrio del lector, es Emilia Pardo Bazán quien guía y teje el entramado a su gusto. La pauta que sigo a la hora de analizar cada uno de estos treinta relatos es distinta, no obedece a una estrategia preconcebida. Al analizar genético-textualmente estos cuentos persigo un único fin: demostrar a través de la presentación ordenada de los testimonios disponibles de cada cuento cómo su creadora matiza y corrige el texto, eliminando lo redundante para quedarse con lo esencial e imperecedero con el paso de los años.

Tenemos cuentos que presentan ilustraciones, sabemos que la autora no era partidaria de las mismas. Se analizan en función del papel que representan en su unión con el texto, su aportación o adelantamiento a la trama del relato.

Hay casos en los que lo que se ofrece a la posteridad es una mezcla del manuscrito y lo publicado en prensa, véase el ejemplo de "Inspiración" / "El modelo". Aquí la autora opta por recuperar el título "Inspiración", que aparecía subrayado en el manuscrito, para su Opera Omnia, desechando "El modelo" que podemos leer en la cabecera madrileña Blanco y Negro.

Disponemos de siete testimonios que tienen como hilo conductor el de corresponderse con cuartillas dactilografiadas: "Al anochecer" / "Los Israelitas", "Puntería", "Remedio infalible", "El triunfo de Baltasar", "Comadre y compadre", "Ejemplo" / "El enemigo" y "Sin respuesta" / "La causa".

Del análisis de los treinta cuentos citados más arriba se deduce que para la escritora marinedina no eran considerados mera literatura del día, los cree merecedores de pasar a la posteridad y dignos de compilarse en su Obra Completa. No suponen un mero sustento económico, los corrige y rehace si lo considera preciso, añade personajes, cambia títulos, matiza la información... en pos de la búsqueda del cuento perfecto, del chispazo final.

La Cuarta Parte está conformada por las Conclusiones y la Bibliografía. Presento a una escritora preocupada por el proceso creativo y la transmisión y fijación de su trabajo. Consciente de la fugacidad de las publicaciones en prensa, opta por salvaguardar sus textos en su Opera Omnia, pero no lo hace de cualquier manera: reflexiona una y otra vez sobre los textos como lo demuestran las diferencias entre las distintas ediciones de aquella, adaptándolos a los tiempos, como ocurre con "El viaje de novios de mister BigPig", cuyo título modifica a "Por España", una vez conocido el resultado de la contienda. No estamos ante una autora que peque de descuido o indiferencia con respecto a su obra. Si han llegado a nosotros vestigios pre-textuales de esta (manuscritos, mecanoscritos, galeradas, anotaciones para posibles trabajos, etc.) ha sido por su propia iniciativa. Como queda demostrado en esta tesis, los documentos previos a la publicación de un texto abren un nuevo e importante campo de trabajo en pos del proceso creativo de un autor, en este caso es Emilia Pardo Bazán.

En los relatos breves es en donde la escritora puede dar muestra de su buen hacer y destreza a la hora de captar al lector, y así no duda en modificar nombres de los personajes, títulos o finales. Incluso en los casos en que no ofrece un gran número de cambios, id 
est, "Los cinco sentidos" o "La salvación de don Carmelo" o "Los padres del Santo", los mínimos trueques tienen como fin buscar la palabra exacta, el término perfecto, en un celoso escrutinio de precisión lingüística que no modifique el desarrollo de la trama.

En esta tesis me he adentrado en el proceso creador y en la fijación textual, desde su existencia íntima y privada en su mesa de trabajo llena de manuscritos, mecanoscritos y galeradas, hasta su faceta más pública vertida en revistas y periódicos, hasta llegar a su culmen en la fijación en su Obra Completa cuyo destino era perdurar en el tiempo y convertir en inmortal a la autora y su trabajo. Es imprescindible estudiar su modus scribendi, poder disponer de textos anotados donde conozcamos fehacientemente las opciones que barajó, por cuál se decantó y en virtud de qué razones lo hizo para llegar a la versión que consideró que debía representarla en el tiempo.

En los anexos que ocupan el segundo volumen de esta tesis doctoral, aporto un fondo documental donde localizo, dato y exhumo las salidas de la totalidad de cuentos que he reunido hasta el momento, lo que va a permitir conocer qué cuentos han tenido más reclamo, caso de "La caja de oro" (se publica hasta en veintisiete ocasiones), cuáles han sido los menos publicados en prensa: "Humano", "Fantaseando" o "En Babilonia", de los que solo disponemos, hasta el momento, de una salida en prensa; al mismo tiempo corrijo datos erróneos presentes en otros inventarios al uso. Presento los relatos siguiendo distintas ordenaciones que facilitan la localización de los lugares donde se publicaron más cuentos de la autora de Morriña. Ubicaciones en algunos casos desconocidas hasta el momento como: El Salvador, Nuevo México, Texas, Panamá, Estados Unidos, México, Puerto Rico, o localidades como Sóller, Orihuela, Teruel, Lérida, Béjar, Tortosa, etc.

El abanico abierto con esta Quinta Parte es enorme, las posibilidades que a partir de esta taxonomía diversificada se ponen al servicio del investigador son múltiples. Hasta el momento los listados que manejábamos eran parciales y de cabeceras singulares, no se disponía de ningún registro exhaustivo de relatos breves con más de doscientas cabeceras revisadas. Este apéndice es, no obstante, susceptible de mejoras puesto que solo he incluido en él los datos que yo misma he podido verificar y contrastar y muchas cabeceras están incompletas. Cada día siguen digitalizándose nuevas publicaciones y completándose las ya existentes y por tanto aparecen distintos hallazgos relacionados con la autora de La Tribuna. 


\section{BIBLIOGRAFÍA}

Axeitos Valiño, Ricardo, e Nélida Cosme Abollo (2005): Os manuscritos e a imaxe de Emilia Pardo Bazán do Aquivo da Familia Pardo Bazán, A Coruña, Real Academia Galega.

Clemessy, Nelly (2006): “Una recuperación de cuentos de Emilia Pardo Bazán en el decenio del sesenta", Emilia Pardo Bazán: los cuentos: I/ Simposio Emilia Pardo Bazán: A Coruña, 27, 28, 29 e 30 de setembro de 2005, González Herrán, José Manuel, Cristina Patiño Eirín y Ermitas Penas Varela (Eds.), A Coruña, Real Academia Galega, pp. 257260.

Ezama Gil, Ángeles (1992): El cuento de la prensa y otros cuentos: aproximación al estudio del relato breve entre 1890 y 1900, Zaragoza, Universidad de Zaragoza.

González Herrán, José Manuel (Ed.) (2011): Emilia Pardo Bazán. Obras Completas XI y XII, Cuentos dispersos, I y II, Madrid, Fundación José Antonio de Castro, Biblioteca Castro.

González Herrán, José Manuel (Ed.) (2014): Emilia Pardo Bazán. El vidrio roto. Cuentos para las Américas. Argentina, Vigo, Editorial Galaxia.

Legal [Clemessy], Nelly (1967-1968) Emilia Pardo Bazán. Contes perdus et retrouvés. Thèse de doctorat, [inédita], Université de Montpelliertomos I-IV.

Martínez Arnaldos, Manuel (1999): “Estrategia de la titulación en los cuentos de E. Pardo Bazán", P. L. Ladrón de Guevara et alii (Eds.), Homenaje al Profesor Trigueros Cano, Pedro Luis Ladrón de Guevara, Antonio Pablo Zamora, Giuseppine Mascali (Eds.), Murcia, Universidad de Murcia: Servicio de Publicaciones.

Novo Díaz, Ma del Mar (2009): "Fondo hemerográfico de y sobre Emilia Pardo Bazán en las Bibliotecas de Gijón", González Herrán, José Manuel, Cristina Patiño Eirín y Ermitas Penas Varela (Eds.), La literatura de Emilia Pardo Bazán, A Coruña, Real Academia Galega, pp, 503-525.

Pardo Bazán, Emilia [1894]: Cuentos Nuevos, OC, tomo X, Madrid, Agustín Avrial.

Pardo Bazán, Emilia [1898]: Cuentos de Amor, OC, tomo XXVI, Madrid, Imprenta de Idamor Moreno.

Pardo Bazán, Emilia [1899]: Cuentos sacro-profanos, OC, tomo XVII, Madrid, Idamor Moreno.

Pardo Bazán, Emilia [1899]: "Carta XIII. Los 'Tickets". -Impresiones", Al pie de la torre Eiffel, OC, tomo XIX, Madrid, Administración, pp. 175-176. Edición digital a partir de Madrid, Establecimiento Tipográfico de Idamor Moreno, [1899?]. Biblioteca Nacional de España. Consultada en http://www.cervantesvirtual.com/obra/al-pie-de-la-torre-eiffel/ el 08/02/20.

Pardo Bazán, Emilia [1901]: En tranvía (Cuentos dramáticos), OC, tomo XXII, Madrid, Idamor Moreno. 
Pardo Bazán, Emilia [1907]: El fondo del alma, OC, tomo XXXI, Madrid, R. Velasco Impresor.

Pardo Bazán, Emilia [1909]: Sud-exprés (Cuentos actuales), OC, tomo XXXVI, Madrid, R. Velasco Impresor.

Pardo Bazán, Emilia (1912): Cuentos trágicos, Renacimiento, Madrid, OC, tomo XLI.

Pardo Bazán, Emilia (1922): Cuentos de la tierra. OC, tomo 43. Póstumo, Madrid, Atlántida.

Patiño Eirín, Cristina (2008): "Periodismo centrífugo y gramática de la cita: Emilia Pardo Bazán en el "Diario de la Marina" (1909-1915)", Serrano Alonso, Javier y Amparo de Juan Bolufer, (Coords.); Rodríguez Fer, Claudio, Cristina Patiño Eirín, Luis Miguel Fernández y Ana Chouciño Fernández (Eds.), Literatura Hispánica y prensa periódica (1871-1931). Actas del Congreso Internacional, Lugo 25-28 de noviembre de 2008. Santiago de Compostela, Universidade, pp. 255-268.

Rodríguez Rodríguez, José Miguel y María Angulo Egea (Coords.) (2010): Periodismo literario. Naturaleza, antecedentes, paradigmas y perspectivas, Madrid, Editorial Fragua.

Ruiz-Ocaña Dueñas, Eduardo (2004): La obra periodística de Emilia Pardo Bazán en La llustración Artística de Barcelona (1895-1916), Madrid, Fundación Universitaria Española.

Sotelo Vázquez, Marisa (2014): "Emilia Pardo Bazán en La España Moderna (18891910)", Anales de literatura española, no 26, pp. 473-498.

Thion Soriano-Mollá, Dolores (2013): “Emilia Pardo Bazán, La forja de una periodista (1875-1880)", Servén Carmen e Ivana Rota (Eds.), Escritoras españolas en los medios de prensa 1868-1936, Sevilla, Editorial Renacimiento, pp. 349-372. 